\title{
Problematizando as representações do mundo natural como delimitação espacial em História Ambiental: Entre a Araucarilandia e a Floresta Ombrófila Mista ${ }^{1}$
}

\section{Discussing the representations of the natural world as spatial demarcation in Environmental History: Between the "Araucarilandia" and Mixed Ombrophilous Forest}

\author{
Ely Bergo de Carvalho*
}

\begin{abstract}
Resumo
O presente artigo busca entender como a Floresta com Araucárias era compreendida como uma floresta homogênea na primeira metade do século XX e como heterogênea no final do século, para, a partir desse exemplo, problematizar os recortes espaciais em história ambiental. Não se trata, aqui, de uma história das controvérsias científicas, de como das primeiras classificações como "Araucarilandia" mudaram para a atual classificação de Floresta Ombrófila Mista (FOM), mas de abordar fontes da tecnoburocracia, governamental e empresarial, para entender a mudança na representação da floresta. As conclusões apontam que as condições técnicas de exploração econômica para exportação da Mata de Araucária levaram a destacar sua relativa homogeneidade, portanto, não se tratava apenas de uma semelhança na composição arbórea, ademais, o aparato de "racionalização" tendia a reduzir a floresta à sua dimensão econômica. Já a heterogeneidade da Floresta Ombrófila Mista não é apenas o resultado de um estudo atento de biogeografia, mas acompanha uma tendência de valorização da sociobiodiversidade, com os debates ambientais da segunda metade do século XX. O que nos leva a postular que as delimitações espaciais de toda boa narrativa histórica devem ser construídas junto com a problemática de pesquisa e não ser um dado $a$ priori.

Palavras-chave: Delimitação Espacial, História Ambiental, Floresta Ombrófila Mista.
\end{abstract}

\footnotetext{
* Doutor em História pela Universidade Federal de Santa Catarina. Professor do Departamento e do Programa de Pós-Graduação em História da Universidade Federal de Minas Gerais. E-mail: elycarvalho@ ufmg.br

${ }^{1}$ Este artigo foi produzido como uma das atividades do projeto "As delimitações espaciais sobre a pesquisa em história ambiental”, financiado pelo CNPq - Chamada Universal 14/2012.
} 


\begin{abstract}
This article seeks to understand how the Araucaria Forest was understood as a homogeneous forest in the first half of the Twentieth Century as heterogeneous and at the end of the century, for, from this example, discuss the spatial delimitation in environmental history. It is not here for a history of scientific controversies, how the first ratings as "Araucarilandia" moved to the current Mixed Ombrophilous Forest ("Floresta Ombrófila Mista - FOM"), but to address sources of techno-bureaucracy, government and business, to understand the change in the forest representation. The conclusions point out that the technical conditions of economic exploitation for export of Araucaria Forest led to highlight their relative homogeneity, so it was not just a difference in tree composition, in addition, the apparatus of "rationalization" tended to reduce forest its economic dimension. Since the heterogeneity of the Araucaria Forest is not just the result of a careful study of biogeography, but follows a trend of appreciation of socio-biodiversity, with environmental debates of the second half of the Twentieth Century. Which brings us to postulate that the spatial boundaries of every good historical narrative must be built with the search problem and not be a given a priori.
\end{abstract}

Keywords: Space Delimitation, Environmental History, Mixed Ombrophilous Forest.

\title{
Introdução
}

A Floresta Ombrófila Mista (FOM) é um ecossistema florestal com chuva durante o ano todo, associado a lugares relativamente altos, que, no Brasil, cobria grande parte dos estados do Rio Grande do Sul, Santa Catarina e Paraná, estando presente pequenas manchas em São Paulo e Minas Gerais, sendo caracterizada, principalmente, pela presença da Araucaria angustifolia, ou pinheiro-do-Paraná, ou ainda, pinheiro brasileiro, com seu tronco reto e sua copa na forma de um "guarda-chuva", formando um extrato superior, sob o qual árvores menores crescem.

Ou em termos técnicos, a FOM é

Caracterizada por uma rica mistura florística que comporta gêneros Australásicos (Drymis, Araucaria) e Afro-Asiáticos (Podocarpus), com fisionomia fortemente marcada pela predominância de pinheiro (Araucaria angustifolia) no estrato superior. Sua área de ocorrência coincide com o clima úmido sem período seco, com temperaturas médias anuais em torno de $18^{\circ} \mathrm{C}$, mas com 
três a seis meses em que as temperaturas se mantem abaixo dos $15^{\circ} \mathrm{C}$. Seus ambientes predominam no Planalto Meridional Brasileiro, em terrenos acima de 500-600 metros de altitude, apresentando disjunções em pontos mais elevados das serras do Mar e da Mantiqueira. ${ }^{2}$

Imagem 1 - Floresta Ombrófila Mista

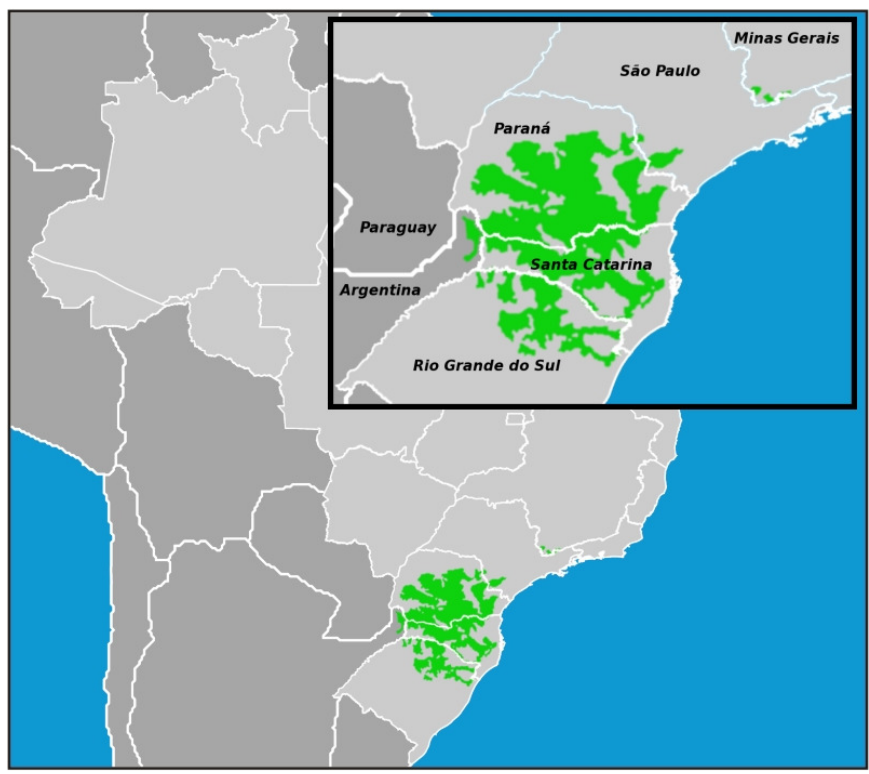

Fonte: http://www.sosmatatlantica.org.br/.

A Floresta Ombrófila Mista também é conhecida como Floresta com Araucárias, Mata de Araucária, Florestas de Pinhais e Mata Preta, faz legalmente parte do bioma da Mata Atlântica, segundo a legislação brasileira, Decreto $n^{\circ} 6.660$, de 21 de novembro de 2008, que regula a proteção da vegetação nativa do bioma Mata Atlântica, estabelecida pela Lei n⿳o 11.428 , de 22 de dezembro de 2006.

O processo de expansão agrícola e crescimento industrial do Brasil, no século XX, se deu às expensas da Mata Atlântica, como bem demonstra Warren Dean. ${ }^{3}$ Sendo que a FOM é hoje um dos ecossistemas mais ameaçados dentro do citado bioma: “Hoje seus remanescentes bem preservados estão

\footnotetext{
${ }^{2}$ BRASIL. Ministério do Meio Ambiente. Mata Atlântica: património nacional dos brasileiros. Brasília: MMA, 2010. p. 65.

${ }^{3}$ DEAN, Warren. A ferro e fogo: A história e a devastação da Mata Atlântica brasileira. São Paulo: Companhia das Letras, 1996.
} 
extremamente fragmentados e não perfazem $5 \%$ da área original, segundo dados do Ministério do Meio Ambiente (2000), ou 3\% segundo Fundação de Pesquisas Florestais do Paraná - FUPEF (1978)." "4 Sendo, hoje, sua sociobiodiversidade reconhecida como um dos fatores para sua preservação. ${ }^{5}$

Imagem 2 - Floresta com Araucárias

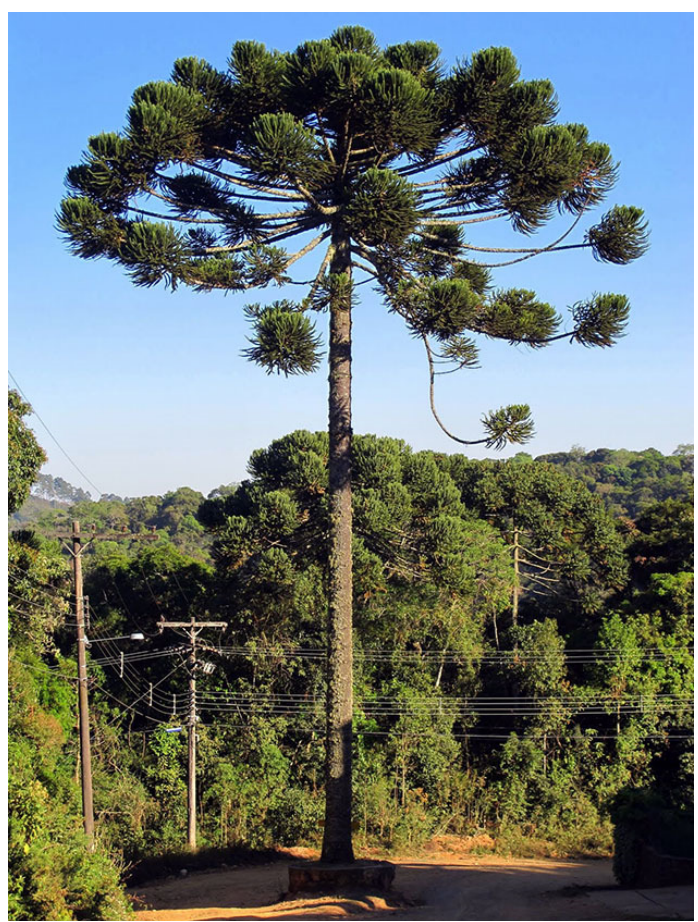

Fonte: http://www.bemparana.com.br/noticia/265011/araucarias-estao-a-tres-passos-da-extincao-completa (Foto: Franklin de Freitas).

Ora, na primeira metade do século XX, um dos primeiros biólogos a procurar classificar tal vegetação, utilizou a denominação de "Araucarilandia"6

\footnotetext{
${ }^{4}$ BRASIL.2010, op. cit., p. 146. Outros autores estimam entre $2 \%$ e $4 \%$ os remanescentes florestais da FOM, ver: GERRA, Miguel P. et. al. Exploração, manejo e conservação da araucária (Araucaria angustifolia). In: SIMÕES, Luciana L., LINO, Clayton F. (Org.) Sustentável Mata Atlântica: a exploração de seus recursos florestais. São Paulo: Ed. SENAC, 2002.

${ }^{5}$ BRASIL, 2010, op. cit., p. 14. Sendo que a biodiversidade é sempre mais enfatizada que a sociobiodiversidade, ver: SILVA, Márcio. A contribuição de florestas de araucária para a sustentabilidade dos sistemas faxinais. Dissertação (Mestrado em Economia) - Universidade Federal do Paraná, Curitiba: 2005.

${ }^{6}$ HOEHNE, F. C. Araucarilandia: observações gerais e contribuições ao estudo da flora e phytophysionomia do Brasil. São Paulo: Secretaria da Agricultura, Industria e Commercio [sic.] do Estado de São Paulo, Secção de
} 
e a legislação que procurou regular o seu uso (Código Florestal, Decreto Federal no 23.793, de 23 de janeiro de 1934), estava pautada na classificação de que a Mata de Araucária era uma floresta homogênea, em oposição aos demais tipos vegetais do Brasil, que seriam florestas heterogêneas. Este artigo procura apontar que a Floresta com Araucárias foi, durante a primeira metade do século XX, entendida como homogênea e como isso mudou, na segunda metade do século XX, passando a ser destacada sua heterogeneidade. Para ao final, exemplificar a problemática de partir de recortes, ditos, naturais para elaborar narrativas de história ambiental.

Primeiro será abordada a dificuldade em desnaturalizar nossas representações de natureza, a partir da noção de uma natureza cornucópia. Em seguida será abordada a construção da representação das Floretas com Araucárias como um tipo florestal, primeiro homogêneo e depois heterogêneo. De tal forma que seja possível defender na conclusão a importância de não naturalizar os recortes espaciais. Ou seja, mesmo em história ambiental, os recortes espaciais devem ser construídos com a problemática e não dados a priori.

\section{Desnaturalizar a noção cornucópia de natureza}

A ideia que a população do Brasil é perdulária com seus recursos naturais, dada a abundância da sua natureza, é presente no imaginário nacional e, muitas vezes, utilizada como fator explicativo de processos históricos. É costumeiro, no senso comum, afirmações simplistas de que a abundância de recursos naturais é a causa do "desperdício" de recursos naturais no Brasil. Sérgio Buarque de Holanda ${ }^{7}$ supera tal materialismo vulgar, mostrando como a imagem de um país paradisíaco foi historicamente construída e procura mostrar como as bases psicossociais do que seria um comportamento perdulário, em relação à natureza, também foram historicamente construídas.

Como afirma Keith Thomas, "é impossível desemaranhar o que as pessoas pensavam no passado sobre as plantas e os animais daquilo que elas

Botânica do Instituto Biológico, 1930. Todavia, como será destacado, as primeiras classificações científicas da Floresta com Araucárias eram atentas, em geral, à diversidade biogeográfica. Como será postulado, a interpretação que a Floresta com Araucárias era homogênea vinha em primeiro lugar do setor empresarial. Contudo, uma classificação científica é também uma representação social e classificar é uma prática produtora de identidades, que tende a separar e homogeneizar. Em especial se considerarmos o final do século XIX e início do XX, momento histórico em que a sanha nacionalizadora do projeto hegemônico de modernidade queria ter o "completo mapa mundi", tudo nomeado, delimitado e disciplinado. ${ }^{7}$ HOLANDA, Sérgio Buarque de. Visão do Paraíso: Os motivos edênicos no descobrimento e colonização do Brasil. 6. ed. São Paulo: Brasiliense, 1996. 
pensavam sobre si mesmas." 8 Um elemento de longa duração no imaginário dos brasileiros, que aliás antecede a própria nação e identidade brasileira, é o motivo edênico. Sérgio Buarque de Holanda já abordou os motivos edênicos no descobrimento e colonização da América Portuguesa e Espanhola, procurando mostrar como os "descobridores, povoadores, aventureiros, o que, muitas vezes, vêm buscar, e, não raro, acabam encontrando, nas ilhas e terra firme do Mar Oceano, é uma espécie de cenário ideal, feito de suas experiências, mitologias ou nostalgias ancestrais." "Como o Novo Mundo não estava previsto na cosmovisão da Europa do "Velho Mundo", a novidade foi incluída a partir da noção de que as novas terras seriam o paraíso terrenal descrito na Bíblia. Para o autor, o tipo de sociedade constituída no Brasil foi voltado para "feitorizar uma riqueza fácil e quase ao alcance da mão"10, contribuíram para a exploração predatória da América Portuguesa, como adverte Holanda:

Teremos também os nossos eldorados. Os das minas, certamente, mas ainda o do açúcar, o do tabaco, de tantos outros gêneros agrícolas, que se tiram da terra fértil, enquanto fértil, como o ouro se extrai até esgotar-se, do cascalho, sem retribuição de benefícios. A procissão dos milagres há de continuar assim através de todo o período colonial, e não a interromperá a Independência, sequer, ou a República. ${ }^{11}$

Roberto Da Matta segue a interpretação de Holanda e a associa ao seu modelo de análise, segundo o qual, a sociedade brasileira teria sua dinâmica caracterizada por um círculo vicioso de "teorias modernas (de caráter universalizante e impessoal) com práticas tradicionais (de cunho particularista e pessoal)". A consequência lógica diante da onda ambiental contemporânea é que: "Se seguirmos o modelo tradicional, acataremos sem restrições e com entusiasmos a proteção da natureza em público, só para negá-la na intimidade de nossas casas e propriedades." ${ }^{12}$ Para o citado autor, em uma sociedade relacional como a nossa, a natureza faz parte das hierárquicas relações sociais, de tal forma que quanto mais próximo alguém estiver da natureza,

\footnotetext{
${ }^{8}$ THOMAS, Keith. 0 homem e o mundo natural: mudanças de atitude em relação às plantas e aos animais, 1500-1800. São Paulo: Companhia das Letras, 1996. p. 19.

${ }^{9}$ HOLANDA, 1996, op. cit., p 315.

${ }^{10}$ HOLANDA, Sérgio Buarque de. Raízes do Brasil. 26. ed. São Paulo: Companhia das Letras, 1995. p. 250.

${ }^{11}$ HOLANDA, 1996, op. cit., p. 334.

${ }^{12}$ DAMATTA, Roberto. Em torno da representação de natureza no Brasil: pensamentos, fantasias e divagações. In: . Conta de mentiroso: Sete ensaios de antropologia brasileira. 2. ed. Rio de Janeiro: Rocco, 1994. p. 91-124. p. 124.
} 
mais baixa será a percepção de seu local na hierarquia social. Sendo que a visão edênica, perpassaria indelevelmente nossa sociedade:

Natureza dadivosa, exploração aventureira e cíclica: Ligada de perto a tudo isso está a ideia de que a natureza pode ser explorada fragmentária e espasmodicamente, de modo que o contato com ela é exterior, sendo realizado apenas para exercer a tarefa econômica de extração. O chamado 'extrativismo predatório', portanto, se fará através do controle e do patrocínio do estado, mas com base em coletividades masculinas, movidas pelo enriquecimento rápido e pelo desejo de subir na escala social em sua própria terra. Foi o que levou Sérgio Buarque de Holanda a chamar o processo de ocupação do território brasileiro de 'feitorização' e não “colonização”, distinguindo duas variantes que, para ele, teriam obedecido a um 'paradigma comum fornecido pelos motivos edênicos'. ${ }^{13}$

Seguindo, também, o modelo interpretativo de Holanda, Warren Dean chegou a afirmar que:

O ódio secular da vida selvagem, expresso pela maioria dos neo-europeus brasileiros, conjugado à disposição geral de saquear o patrimônio nacional em proveito privado, como se o país ainda fosse uma colônia e houvesse algum outro El Dorado em outras índias para compensar quando nada de valor restasse dessa morada temporária, talvez seja suficiente para explicar, em termos gerais, por que a floresta está desaparecendo. ${ }^{14}$

Todavia, em busca de uma "mentalidade" demasiadamente homogênea, os autores acabaram perdendo a diferença, no tempo e no espaço, das relações entre sociedades humanas e os ambientes no Brasil. Dessa forma, segundo Diogo de Carvalho Cabral, tanto Holanda como Dean, em nome de uma eficácia econômica, inspirada nas ideias liberais e no modelo do centro do sistema mundo, criticam como perdulária e ineficiente a sociedade brasileira. ${ }^{15}$ Não cabe aqui avaliar se houve no Brasil um comportamento perdulário ou uma sofrível transformação de "capital natural em capital social", mas para o historiador, uma questão central é perguntar: como estes critérios

\footnotetext{
${ }^{13}$ Ibidem, p. 107.

${ }^{14}$ DEAN, op. cit., p. 298-299. Todavia, José Augusto Drummond, ao avaliar a tese de Dean sobre o processo de "transformação de capital natural em capital social", afirma que: "Sem negar que houve desperdícios incríveis no aproveitamento dos recursos da Mata Atlântica e que há desigualdades sociais escandalosas na sociedade brasileira contemporânea, sinto que Dean foi, neste livro, implacável com os habitantes das terras florestadas brasileiras, desde os anônimos indígenas coletores e caçadores até os modernos ambientalistas urbanos". DRUMMOND, José Augusto. Mata Atlântica: A História de uma Destruição. Estudos Históricos, Rio de Janeiro, v. 9, n. 17, p. 239-250, 1996. p. 247.

${ }^{15}$ CABRAL, Diogo. de C. Economia do desperdício, ecologia da destruição: historiografia, ambientalismo e o debate político contemporâneo. Esboços, Florianópolis, v. 4, n. 18, p. 73-104, 2007.
} 
de eficácia foram historicamente construídos? Em geral, tais "critérios" são mais contingentes do que parecem à primeira vista.

Diogo Cabral, por exemplo, aborda esta questão no período colonial, e argumenta que: Dean desenvolve a ideia de que "a taxa de conversão da floresta em capital (fixo e de giro) foi irrisória ao longo de todo o período de domínio português". Dessa forma, Dean espera um capitalismo que maximize a produção e a eficiência. E não percebe que no Brasil colônia há uma "matriz cultural" diferente. A extração do sobre-trabalho era investida, em grande parte, não na reprodução ampliada do capital, e sim, na reprodução da hierarquia social, entre outros, com a compra de escravos. Dessa forma, Cabral, apoiado em uma dada interpretação sobre a socioeconomia colonial, afirma:

[...] que a questão não é, absolutamente, se a economia brasileira produziu capital internamente ou não, mas sim como esse capital era 'aplicado' ou, em outras palavras, como a renda era alocada. Dependendo das motivações sociais e políticas dos agentes gerenciadores dos mecanismos de acumulação, uma floresta pode se transformar numa estrada ou num pelourinho, num moinho ou numa igreja - todas estas incontestes manifestações de riqueza, a única diferença sendo a matriz cultural a partir da qual elas são percebidas e valoradas. ${ }^{16}$

Dessa forma, faltaria, nas abordagens criticadas por Cabral, uma maior atenção para a cultura. E isso não se limita ao período colonial. Recorrentemente, em nome de critérios de eficácia econômica a-históricos, se condena como irracionais as práticas sócio-cultural-ambientalmente enraizadas do Outro. Ou, como afirma Stefania Barca: a "consciência ambiental moderna ocidental [...] está fundada sobre a ideia [em geral equivocada] de que a crise ambiental era causada pelas comunidades tradicionais enquanto incapazes de uma gestão racional e moderna da natureza." ${ }^{17}$ Tal condenação, em geral, é feita a partir de uma homogeneizadora racionalidade econômica que se subtrai de indagar o tempo. ${ }^{18}$

Mas isto não significa que ideias e comportamentos de longa duração não podem ser identificados. Dessa forma, por exemplo, o motivo edênico deve ser entendido na longa duração no imaginário social, mesmo que não deva ser tomado como um todo homogêneo. Em geral, os elementos de

\footnotetext{
${ }^{16}$ Ibidem, p. 92-93.

${ }^{17}$ BARCA, Stefania. Natureza, política e "desordem das águas". Teorias da vulnerabilidade ambiental na Europa Mediterrânica (sécs. XVIII e XIX). In: NODARI, Eunice S. CORREA, Silvio M. de S. (Orgs). Migrações e Natureza. São Leopoldo: Oikos, 2013. p. 145-163, p. 163.

${ }^{18}$ LEFF, E. Construindo a História Ambiental da América Latina. Esboços, Florianópolis, n. 1, v. 13, p. 11-30, 2005.
} 
longa duração não se mantêm por serem sempre iguais a si mesmos, mas por terem sido apropriados em diferentes configurações sociais, em diferentes contextos, nos quais eles são reelaborados e, neste processo, muitas vezes se amplificam. Mas não entenderemos a força de tais elementos se não percebemos que eles se legitimam e tiram força de uma tradição de longa duração. ${ }^{19}$ Dessa forma, por exemplo, Pero Vaz de Caminha, ao afirmar que "nesta terra se plantando tudo dá", e Lysia Maria Cavalcanti Bernardes afirma, sobre a região cafeeira paranaense em meados da década de 1950, que o "solo, cuja grande riqueza é considerada pelo desbravador como inesgotável" 20 , formam uma tradição edênica, apesar de serem textos em contextos bem diferentes.

o "gostar de levar vantagem em tudo", o "feitorizar uma riqueza fácil ao alcance da mão" podem ser parte de um "habitus nacional", ${ }^{21}$ traços de um modelo da cultura brasileira, mas não podem ser tomados como um padrão homogêneo de comportamento e valores, pois fazem que com o brasileiro seja julgado em demasiada severidade em relação à sua relação com o mundo natural e silencia sobre práticas e valores outros que foram construídos na rica sociobiodiversidade do que é hoje o Brasil.

A noção de uma natureza cornucópia, associada ou não ao motivo edênico, é outro desses elementos presentes na longa duração. Como lembra José H. R. Gonçalves: “Algo que não era uma particularidade brasileira, uma vez que o sentimento de inesgotabilidade do meio-ambiente alcançava, até não muitos anos atrás, a maior parte dos povos da Terra."22 Dessa maneira, por exemplo, tanto o fisiocrata do século XVIII, que acreditava que a riqueza provinha da agricultura, pois era a atividade em que os recursos efetivamente eram ampliados, afinal se plantava um grão e se colhia muitos; como os economistas neoclássicos que afirmavam que a riqueza provinha do trabalho, como se os elementos como a água, o ar, os minerais fossem meras externalidades à economia, que só tinham valor a partir do toque humano; em todos os casos o mundo natural é entendido como um grande depósito inesgotável.

\footnotetext{
${ }^{19}$ A inspiração aqui é evidentemente feita na obra de SAHLINS, Marshall. História e Cultura: Apologias a Tucídides. São Paulo: Zahar, 2006.

${ }^{20}$ BERNARDES, Lysia Maria Cavalcanti. O problema das "frentes pioneiras" no Estado do Paraná. Revista Brasileira de Geografia. v. 15, n. 3, jul.-set. p. 3-52, 1953. p. 8.

${ }^{21}$ ELIAS, Norbert. Os Alemães: A luta pelo poder e a evolução do habitus no século XIX e XX. Rio de Janeiro: Zahar, 1997.

${ }^{22}$ GONÇALVES, José Henrique Rollo. Quanto a imagem publicitária vira evidência factual: versões e reversões do Norte (Novo) do Paraná - 1930-1970. In: DIAS, Reginaldo Benedito. GONÇALVES, José Henrique Rollo. (Orgs.). Maringá e o Norte do Paraná: Estudos e história regional. Maringá: EDUEM, 1999. p. 87-122. p. 115-116.
} 
Todavia, como já foi argumentado, tais ideias de longa duração devem ser sempre matizadas e compreendidas dentro dos contextos específicos. Por exemplo, segundo Araújo, houve uma passagem do "mecanicismo clássico" para o "mecanicismo termodinâmico" no século XIX, ou seja, de uma natureza como uma máquina inesgotável, movimentada por Deus, para uma natureza como máquina inesgotável, mas movimentada pelo ser humano, ou, talvez fosse melhor dizer, movida pela tecnologia. Para tal autor, entretanto, houve uma persistência do "mecanicismo clássico" no Brasil, com a hegemonia da ideia de um "país essencialmente agrícola" por parte da elite ligada aos interesses agrários, no qual caberia aos seres humanos apenas gerir a riqueza produzida pela natureza e não ser o motor produtor da riqueza..$^{23}$

Ao menos nas fronteiras de colonização, aparentemente, a imagem de uma natureza como motor do progresso parece ter sido mais persistente. Romanello afirma que, somente nos anos 1940/1950, houve uma "transição discursiva" em relação à terra, no Vale do Paranapanema paulista, de uma terra como paradisíaca que garante por si mesmo o progresso, para uma terra que demanda a aplicação de tecnologia:

[...] durante a década de 1940, [...] imagem de riqueza começa a ceder espaço para um discurso de fundo, mais técnico; a terra rica, passa a não ser mais necessariamente a fonte da riqueza, pois faz-se necessário que a agricultura aplique 'cuidados científicos' ao solo, para que ele possa produzir, mais e melhor. ${ }^{24}$

Contudo, ainda é possível encontrar, na historiografia, a noção naturalizada, no qual a abundância de recursos seria uma armadilha responsável pelo seu suposto mau uso. Um autor consagrado na história regional do Paraná, Ruy Wachowicz, faz duras críticas à indústria madeireira no século XX naquela região:

Sendo a serraria uma atividade nômade, não se integra na região em que está estabelecida. Esgotada a floresta, a serraria é transferida para outro lugar e forma, em torno de si, um núcleo populacional característico, com dezenas de casas para operários, mercado, farmácia, etc, tudo pertencendo à companhia exploradora. Caracterizam-se os seus trabalhadores pelo baixo nível de vida fruto deste sistema. Por se encontrarem, na maioria, as serrarias na 'boca do sertão'. ${ }^{25}$

\footnotetext{
${ }^{23}$ ARAÚJO, Hermetes Reis de. da Mecânica ao Motor: A idéia de natureza no Brasil no final do século XIX. Proj. História, São Paulo, n. 23, p. 151-167, nov. 2001.

${ }^{24}$ ROMANELLO, Jorge Luiz. Imagens e visões do Paraíso no Oeste Paulista: Um Estudo do Imaginário Regional. Dissertação (Mestre em História) - UNESP, Assis.1998. p. 15.

${ }^{25}$ WACHOWICZ, Ruy Christovam. História do Paraná. 6. ed. amp. Curitiba: Vicentina, 1988. p. 205.
} 
E conclui que: a "serraria deixa por onde passa, uma região devastada, sem ter contribuído para a fixação duradoura da população". Explicando que a "falta de mentalidade bem formada da população provocou, em poucos anos, o esgotamento das reservas." 26

E mesmo em trabalhos mais recentes, como o que visa abordar a atividade de serrarias no norte do Rio Grande do Sul, de Liliane I. M. Wentz, continuam a simplificar o modelo de ação e cognição dos agentes, projetando uma noção cornucópia simples no Outro, o que reforça uma representação de perdulário e destruidor que estigmatiza os "brasileiros". A autora afirma, sobre os madeireiros, em torno da década de 1930:

Geralmente, não havia uma exploração racional, ou seja, não se dava importância ao reflorestamento por se acreditar na permanente abundância do mato; assim, os madeireiros e afins iam derrubando as florestas. ${ }^{27}$

Entretanto, como veremos, nos documentos citados pela própria autora e alhures, o complexo madeireiro estava muito mais próximo de um "mecanicismo termodinâmico" do que do "mecanicismo clássico", ou seja, se o recurso era pensado como inesgotável, o era por força da tecnologia e não da natureza.

\section{A tecnologia cornucópia: uma floresta homogênea}

Foi após a Primeira Guerra Mundial que o Brasil passou de importador a exportador de madeira, isso graças a um complexo industrial madeireiro que se formou no Sul, para explorar, basicamente, a Floresta com Araucárias. Alguns trabalhos apontam que a ampliação da fronteira agrícola e a abundância da floresta era um dos principais fatores para a ampliação do setor, sem a preocupação com a sua "sustentabilidade" econômica ou ambiental. ${ }^{28}$ Mas ao analisar os relatórios do escritório regional do Paraná do Instituto Nacional do Pinho - INP, órgão criado em 1942, o que pode ser percebido é que havia uma preocupação com o esgotamento das Florestas com Araucárias, mas que era minimizado, pois havia uma crença e uma aposta de que o desenvolvimento tecnológico do setor de silvicultura solucionaria

\footnotetext{
${ }^{26}$ Ibidem, p. 205 e 206.

${ }^{27}$ WENTZ, Liliana Irma Mattje. Os caminhos da madeira: região norte do Rio Grande do Sul 1902-1950. Passo Fundo: UPF, 2004. p. 14. (Grifo meu).

${ }^{28}$ LAVALLE, A. M. A madeira na economia paranaense. Dissertação (Mestrado em História) - Universidade Federal do Paraná, UFPR, Curitiba, 1974.
} 
todos os problemas da indústria madeireira. Tal crença no progresso se mostrou infundada e o setor passou por várias crises.

O Instituto Nacional do Pinho foi instituído pelos Decretos-leis n²3.124, de 19 de março de 1941, e 4.813, de 8 de outubro de 1942. 0 artigo primeiro do decreto de criação do INP previa que ele seria o "órgão oficial dos interesses dos produtores, industriais e exportadores de pinho". ${ }^{29}$ Sendo que se constituiu aproveitando a estrutura do Serviço do Pinho, da extinta Comissão de Defesa da Economia Nacional, tendo o Serviço do Pinho substituído ou encampado o Sindicato da Indústria de Serrarias. ${ }^{30}$ Dessa maneira, segundo histórico publicado no periódico oficial do INP, o Anuário Brasileiro de Economia Florestal, o INP "não foi delineado, projetado e definido preventivamente, mas somente tomou forma oficial, como órgão autárquico, após impor, pelo imperativo das necessidades, a razão e a forma de sua constituição." ${ }^{31} \mathrm{O}$ citado histórico assim narra a situação que levou à criação do INP:

A destruição sistemática e ininterrupta de nossas reservas florestais, observada, principalmente, no planalto meridional brasileiro, onde se instalou uma poderosa indústria de exportação madeireira, vinha causando profundas e justificadas apreensões quanto ao destino que estava reservado a tão preciosa riqueza.

Generalizou-se, assim, por quase todo o território nacional, um grande clamor contra as derrubadas inclementes das nossas florestas, ao mesmo tempo que se reclamavam medidas urgentes sobre o reflorestamento. [...]

Por sua vez, a iniciativa particular, sem preparo nem assistência técnica para proceder a exploração e, muito menos, a reconstrução florestal, pouco ou nada podia realizar, mesmo porque, manda a verdade dizer, o imediatismo dos negócios e a improvisação da indústria não lhe permitia pensar na solução de tão grave quanto importante problema. [...]

Cumpria, portanto, uma providência do Estado, capaz de garantir condições de sobrevivência para nosso já tão dilapidado patrimônio florestal. A adoção de uma política orientada nesse sentido teve como consequência a criação do Instituto Nacional do Pinho. ${ }^{32}$

O chefe do Serviço Florestal do Ministério da Agricultura, A. de Miranda Bastos, narra em 1961, que quando entrou no Serviço Florestal em 1930, havia no Paraná "uma febre contagiante de derrubar pinheiros,

\footnotetext{
${ }^{29}$ BRASIL. Decreto-Lei Federal nº 3.124, de 1941.

${ }^{30}$ INP - Instituto Nacional do Pinho. Delegacia Regional do Paraná. Relatório 1955. Curitiba, 1956.

${ }^{31}$ Idem., p. 32.

32 O INSTITUTO Nacional do Pinho e a questão florestal. Anuário Brasileiro de Economia Florestal, Rio de Janeiro, p. 401-408, 1948. p. 401.
} 
arrastar toras, montar serrarias, sem ninguém se importar de saber se havia transporte e compradores para toda a madeira produzida." ${ }_{33}$

Em 1939, a situação chegara a um ponto dramático: 1.350 .000 metros cúbicos de pinho serrado esperavam que 45.000 vagões viessem apanhá-los. Não havia possibilidade de transporte e de consumo se não para um terço desse volume, mas as serrarias continuavam trabalhando e se multiplicando. ${ }^{34}$

Apesar da criação do INP conseguir "debelar essa crise" ${ }_{35}$, o setor madeireiro continuou a sofrer com crises periódicas de superprodução. $\mathrm{O}$ setor econômico madeireiro foi marcado pela instabilidade, durante todo o período de existência do INP. Os preços internacionais eram baixos devido à baixa qualidade do produto brasileiro e à grande oferta do produto, ao mesmo tempo em que os meios de transporte eram insuficientes, causando, frequentemente, a deterioração da madeira a ser exportada por falta de transporte. As políticas de cotas e autorização de produção, para adequação da produção à demanda e à capacidade de transporte, foram medidas tomadas pelo INP, mas a ação do Instituto não foi suficiente para otimizar o setor. ${ }^{36}$

Um jornal sul-rio-grandense expressa bem tal situação à época da criação do INP:

'A criação do Instituto Nacional do Pinho era uma imperiosa necessidade. Era imprescindível uma organização autônoma para pôr ordem, à desorganização da indústria e comércio de madeiras, pois, estávamos destruindo a esmo, sem proveito para o país, as suas reservas florestais, numa concorrência desenfreada e descabida, em proveito do comprador estrangeiro. [...] [0 que] corresponde perfeitamente, aos anseios da classe madeireira. Era, mesmo, preciso que os negócios do pinho fossem devidamente regulados, em benefício não só dos produtores, exportadores e beneficiadores, como também, e principalmente da própria riqueza nacional'. ${ }^{37}$

A "riqueza nacional" deveria ser racionalizada com o controle e regulação da produção. A criação do INP marca uma conjuntura em que já estava clara, pelo menos para as lideranças do setor madeireiro e políticos, a escassez da Floresta com Araucárias, para a qual, tanto a legislação florestal

\footnotetext{
${ }^{33}$ BASTOS, A. de Miranda. O drama da floresta de pinheiro brasileiro. Anuário Brasileiro de Economia Florestal, Rio de Janeiro, p. 69-80, 1961. p. 73.

${ }^{34}$ Ibidem, p. 73.

${ }^{35}$ Ibidem.

${ }^{36}$ LAVALLE, 1974, op. cit., p. 140 e passim.

${ }^{37}$ CRIAÇÃo do Instituto Nacional do Pinho. Jornal da Serra, Carazinho, n. 765, 24 mar. 1941. p. 11. apud WENTZ, 2004, op. cit., p. 125.
} 
quanto o INP, se voltara. Sua estratégia para resolver o "problema florestal" era fomentar o reflorestamento.

Mas tal reflorestamento industrial massivo somente se efetivaria após a promulgação do Código Florestal de 1965, graças ao acúmulo técnico até então realizado e, principalmente, aos incentivos fiscais do Governo Federal. Sendo que o órgão responsável, na esfera federal, pela política florestal passaria a ser o Instituto Brasileiro de Desenvolvimento Florestal (IBDF), sucessor do INP. ${ }^{38}$

No ano de 1953 ocorreu, na cidade de Curitiba, o I Congresso Florestal Brasileiro. Reuniram-se políticos, como o governador do Estado, cientistas e técnicos na área florestal e empresários do comércio e indústria madeireira, para debater o futuro das florestas brasileiras. ${ }^{39}$ Neste artigo é utilizado como fonte, principalmente, os relatórios do escritório Regional no Paraná do INP, sobre o citado Congresso que foi promovido pelo INP.

A exploração florestal, à época, apresentava uma classificação das florestas, dividindo-as entre homogêneas e heterogêneas. Os princípios que nortearam a elaboração do primeiro Código Florestal brasileiro, de 1934, poderiam assim ser sintetizados, por um de seus elaboradores:

O Brasil, talvez o país que possua maior área florestada é pobre de florestas homogêneas. Verdadeiramente merecedora desse qualificativo só temos os pinhais da chamada Araucarilandia [mata de araucária], nos Estados do Paraná e Santa Catarina.

Ora, só as florestas homogêneas permitem exploração industrial em grande escala com vantagem econômica, porque a mão-de-obra nas heterogêneas, é muito dispendiosa, encarecendo o custo da produção. ${ }^{40}$

Nas heterogêneas florestas tropicais que compunham a grande maioria das florestas brasileiras, apenas algumas espécies tinham as qualidades então exigidas pelo mercado consumidor, e elas estavam espalhadas com apenas alguns indivíduos da espécie no meio de uma densa floresta. Dessa forma, dado os limites, técnico e econômico, percebidos pelos legisladores, para as florestas homogêneas havia formas rígidas de conservação e otimização do uso, já para as florestas heterogêneas, a legislação era mais "flexível". ${ }^{41}$

\footnotetext{
${ }^{38}$ IBDF - Instituto Brasileiro de Desenvolvimento Florestal. Delegacia Estadual do Paraná. Relatório 1967. Curitiba, 1968. p. 2.

${ }^{39}$ INP - Instituto Nacional do Pinho. Delegacia Regional do Paraná. Relatório 1953. Curitiba, 1954. p. 116-117.

${ }^{40}$ PEREIRA, Osny Duarte. Direito Florestal Brasileiro. Rio de Janeiro: Borsoi, 1950. p. 140.

${ }^{41}$ BOHN, Noemia. A legislação ambiental e sua implementação frente a degradação da cobertura florestal no vale
} 
Segundo o Código Florestal de 1934, o tratamento dado às florestas homogêneas previa, em seu artigo 49, que "o corte far-se-á de forma a não abrir clareiras na massa florestal"42, ou seja, "não admitia, portanto, o corte raso. E no parágrafo único, ficava estabelecida a inadmissibilidade do uso das terras das florestas homogêneas para outro que não o do reflorestamento, significando na prática que a área da floresta homogênea não poderia ser reduzida" ${ }^{43}$ Todavia, hoje restam menos de $5 \%$ da área original que cobria boa parte do Sul do Brasil e de Missiones na Argentina - da "homogênea" Floresta Ombrófila Mista. Sendo que o período de vigência do Código Florestal de 1934 (até 1965) foi o auge da colonização dirigida e da indústria madeireira na Floresta com Araucárias.

Já para as florestas heterogêneas, ou seja, todas as demais florestas brasileiras, o tratamento era outro:

A exploração intensiva era permitida nas florestas heterogêneas, o tipo de floresta mais comum no Brasil, e admitia o corte raso em $3 / 4$ partes das florestas existentes na propriedade na data em que o Código entrou em vigor. Isso significa que, de acordo com o artigo 23, um proprietário poderia derrubar $75 \%$ das matas da sua propriedade desde que elas não estivessem enquadradas como 'florestas protetoras' ou 'remanescente'. [...] Mas se isso não bastasse, há um outro artigo que permitia a exploração dos $25 \%$ restantes, caso eles não estivessem enquadrados como 'floresta protetora' ou 'remanescente'. Para isso, bastava que o proprietário assinasse perante a autoridade florestal, termo de obrigação de replantio e trato cultural por prazo determinado, com garantias de que substituiria aquela quarta e última parte da floresta heterogênea por uma floresta homogênea. Era a legalização do corte raso. ${ }^{44}$

Enquanto as florestas homogêneas deveriam ser "substituídas por mudas da mesma espécie ou de outra essência florestal julgada preferível”, na floresta heterogênea "a substituição" poderia "ser feita por espécie diferente das abatidas, visando a homogeneidade da floresta futura e a melhoria da composição florística". ${ }^{45}$ De toda forma, a lei incentivava a substituição da "caótica" floresta, seja a homogênea ou a heterogênea, por uma "natureza nova", "melhorada" pelo ser humano. A floresta "melhorada" era

\footnotetext{
do Itajaí. Dissertação (Mestrado em Ciências Humanas - Especialidade Direito) - Universidade Federal de Santa Catarina, Florianópolis, 1990. p. 139-141.

${ }^{42}$ BRASIL, Ministério da Agricultura, Conselho Florestal Federal. Código Florestal. Florianópolis: Imprensa Oficial do Estado, 1949, art. 49.

${ }^{43}$ BOHN, op. cit., p. 139-140.

${ }^{44}$ Ibidem, p. 139-140.

${ }^{45}$ BRASIL, 1949, op. cit., art. 50 (Grifo meu).
} 
a floresta controlada, produtiva e efetivamente homogênea: a floresta ideal era a produzida pela silvicultura.

O chefe do Serviço Florestal do Ministério de Agricultura, A. de Miranda Bastos, afirmava que a solução para o "drama da floresta de pinho" não era proibir o corte, e sim, seguir a estratégia de efetuar reflorestamento:

Não se trata de proibir o corte. Segundo a ciência florestal, as árvores produtoras de madeira devem ser cortadas assim que apresentem as dimensões próprias a cada indústria.

Uma floresta tecnicamente explorada tende a produzir maior volume de madeiras de melhor qualidade, que o volume que produzia no começo. ${ }^{46}$

E o livro "Direito Florestal Brasileiro" editado em 1950, pelo INP, traz em epígrafe a missão e vinculação do órgão: "Este livro visa mostrar o direito de nossas florestas, para que nunca se extingam as SERRARIAS DO BRASIL". E que se tratava de "elevar a atividade florestal ao mesmo nível para o qual marcham a agricultura e a pecuária racionalizadas." ${ }^{47}$ E racionalizar aqui significa fazer uma racionalização, nos termos de Edgar Morin, ou seja, pretendia-se reduzir toda a complexidade da paisagem florestal a um único princípio, o da produção. ${ }^{48}$

Todavia, no início da atuação do INP não havia, no Brasil, um arcabouço de conhecimentos tecno-científicos capazes de sustentar um reflorestamento industrial. Nem mesmo os critérios técnicos de padronização para a exportação do pinho brasileiro haviam sido estabelecidos, sendo este um dos elementos que se buscou estabelecer para ampliar o mercado externo, já que isto garantia um padrão de qualidade ao comprador estrangeiro. Mais tarde, em meados da década de 1950, foi estabelecida a padronização de medidas e classificação para a peroba rosa. ${ }^{49}$

\footnotetext{
${ }^{46}$ BASTOS, 1961, op. cit., p. 79.

${ }^{47}$ PEREIRA, 1950, op. cit., p. V, XI (grifo meu - caixa alta é grifo no original).

${ }^{48}$ Tal sanha racionalizadora não implicava o desconhecimento de uma dimensão do que chamaríamos hoje de serviços ambientais da Floresta, pelo contrário era um dos motivos para cuidar ainda mais de sua "racionalização" e, também, não implicava na inexistência de uma "crítica ambiental" que reconhecia outras dimensões da floresta, mas seguramente estes não estavam nas posições de controle da gestão estatal da floresta, ver: CARVALHO, Ely Bergo de. 0 estado jardineiro e a gestão das florestas: uma história do Departamento de Geografia, Terras e Colonização na gestão do sertão paranaense (1934-1964). In: KLANOVICZ, Jó; ARRUDA, Gilmar; CARVALHO, Ely Bergo de. (Orgs.). História ambiental no sul do Brasil: apropriações do mundo natural. São Paulo: Alameda, 2012. p. 149-178 e MORIN, Edgar. Ciência com Consciência. 3. ed. Rio de Janeiro: Bertrand Brasil, 1999.
}

${ }^{49}$ INP, 1956, op. cit. Peroba rosa é um nome comum a várias espécies botânicas do género Aspidosperma. 
Quanto à tecnologia para o plantio, uma série de instituições, estatais e privadas, em esforços esparsos, foram reunindo elementos que vão dos espaçamentos até os cuidados técnicos necessários para o cultivo, em especial da Araucaria angustifólia, o pinheiro brasileiro. O INP participou desse esforço, mas em 1948, ainda poderia se afirmar que eram necessárias pesquisas básicas:

Necessitamos com presteza de conhecimentos gerais do problema [do reflorestamento] que ainda não foram sequer iniciados. A organização de um programa de estudos preliminares florísticos, geográficos, geológicos, pedológicos, entomológicos, zoológicos em geral e, finalmente, meteorológicos, o I.N.P. está dedicando sua melhor atenção. ${ }^{50}$

Durante o I Congresso Florestal Brasileiro, o madeireiro Ruy Itiberê da Cunha afirma, com um pouco de exagero, que: "Saímos do marco zero, em matéria de florestamento, pois até aparecer o Instituto Nacional do Pinho, não tínhamos nada feito." ${ }_{51}$ E narra um acontecimento emblemático: uma reunião que foi a "semente" do INP, em que apresentou um trabalho sobre o reflorestamento do pinheiro brasileiro, baseado no técnico Navarro de Andrade, durante a reunião apresentou um trabalho e narra que:

Enquanto procedia à leitura daquele trabalho, notei que Navarro de Andrade
sorria e fiquei intrigado com aquele sorriso. E pensei: teria copiado alguma
coisa errada? Teria interpretado algo errado? E cada vez que olhava para
Navarro de Andrade, ele sorria. Quando terminei de leer [sic] o meu trabalho,
perguntei-lhe porque tinha rido enquanto eu falava e ele me respondeu
que tinha feito exatamente aquilo que eu dizia e que havia escrito, mas que
tinha sido um fracasso, por isso tinha achado graça, quando falei em fazer
exatamente o que estava em sua obra e que, infelizmente, já ele mesmo
havia condenado. Vejam por isso, como tudo era difícil. Acompanhando o
Instituto desde a sua fundação, nele tenho trabalhado algumas vezes e me
permito, empregando uma palavra pouco parlamentar, dizer-vos que todas as
'burradas' em matéria florestal que o Instituto tenha feito, as fez para evitar
que os particulares e os interessados viessem a fazê-las. ${ }^{52}$

Houve um debate no I Congresso Florestal sobre se a formação de pessoal qualificado para a silvicultura deveria ser feita por agrônomos que se especializariam na cultura florestal ou por cursos específicos de engenharia florestal. Sendo que, nas conclusões do Congresso, foi feito constar a neces-

\footnotetext{
${ }^{50}$ INP, 1948, op. cit., p. 408.

${ }^{51}$ INP, 1954, op. cit., p. 133.

${ }^{52}$ Ibidem, p. 132-3.
} 
sidade da "criação em regime de urgência, da cadeira específica de Silvicultura, nas escolas agronômicas do Brasil". ${ }^{53}$ Isto porque "a quem cabe o lado natural do reflorestamento é ao agrônomo: ao comércio e à indústria cabe o amparo ao técnico." ${ }^{54}$

A estratégia de reflorestamento racional estava pautada em uma confiança na tecnociência que não poderia ser questionada..$^{55} \mathrm{O}$ que se expressa na afirmação exemplar de Carvalho Araújo quando enfatiza que era "preciso usar da técnica na questão florestal. E que a ciência já tinha dito o que era possível fazer." ${ }^{56}$ A tecnociência não seria capaz apenas de orientar o sistema de produção, mas também, disciplinar os trabalhadores, como "diz o dr. Castro Velloso": os industriais precisavam "de agrônomos capazes de elevar o nível intelectual do homem do campo." ${ }^{57}$ Mas a gritante falta de trabalhadores especializados até mesmo para os poucos Parques Florestais, indicava a impossibilidade de uma ação mais sistemática de tais técnicos.

Quanto à pesquisa para o reflorestamento, nos anos seguintes, cada vez mais, elas iriam se direcionar para o estudo de espécies exóticas que apresentavam crescimento mais rápido e forneciam um maior retorno econômico diante do "rápido desaparecimento dos nossos pinhais". ${ }^{58}$ Como se afirmou durante o Congresso Florestal: "Entre as muitas experiências realizadas, surgiu como esplêndida solução o 'pinus elliottii', trazido para o Brasil pelo eminente Engenheiro Florestal Dr. Helmuth Paulo Krug da Secretaria de Agricultura de São Paulo." ${ }^{59}$

A estratégia de reflorestamento racional e a tecnociência indicam uma mudança na ideia de uma natureza cornucópica. Não era a aposta em uma inesgotabilidade que aparece nos anais do I Congresso Florestal Brasileiro ou nos relatórios do INP.

Mas o que aparece nas fontes é que havia uma forte condenação do "desflorestamento irracional", em termos conservacionistas/utilitaristas, até mesmo nas fontes jornalísticas citadas por Liliane I M. Wentz. ${ }^{60}$ Indica a

\footnotetext{
${ }^{53}$ Ibidem, p. 111.

${ }^{54}$ Ibidem, p. 143.

${ }^{55}$ CARVALHO, 2012, op. cit., p. 149-178.

${ }^{56}$ INP - Instituto Nacional do Pinho. Delegacia Regional do Paraná. Relatório 1953. Curitiba, 1954. p. 136. (grifo meu).

${ }^{57}$ Ibidem, p. 143

${ }^{58}$ Ibidem, p. 70

${ }^{59}$ INP - Instituto Nacional do Pinho. Delegacia Regional do Paraná. Relatório de 1965. Curitiba, 1966. p. 17.

${ }^{60}$ WENTZ, op. cit.
} 
citada autora, para o caso do norte do Rio Grande do Sul, inclusive, que houve a formação de cooperativas de madeireiros, visando o reflorestamento e a execução do Código Florestal. ${ }^{61}$ Evidentemente, tais atividades não foram amplamente e calorosamente apoiadas pelos madeireiros. Mas elas, como a presença e discurso das elites do setor madeireiro, representado em seus sindicatos, apontam que, já nos anos 1930 e 1940, estava clara a limitação da "floresta natural", enquanto fonte de madeira.

Luiz Alberto Langer afirma que o I Congresso Florestal Brasileiro foi um marco importante para o desenvolvimento de uma "consciência florestal" e que o "otimismo abstrato com que a indústria madeireira sempre considerou as reservas florestais industrializáveis, passou a ser substituído por uma recente atenção à realidade evidenciada nas discussões daquele memorável certame." ${ }^{2}$ Langer, em 1966, argumentou ainda que, com "o correr dos anos, foi aos poucos se diluindo a ilusória euforia antiga, que as enormes reservas de pinheiros no sul do país eram suficientes ao suprimento das nossas necessidades de madeiras de pinho durante séculos". ${ }^{63}$ Por mais que ainda hoje a indústria madeireira pareça, às vezes, se comportar como se as florestas fossem inesgotáveis, os modelos de ação e cognição são mais complexos do que podem aparentar.

Em tal caso é em uma visão de mundo moderna mecanicista, ${ }^{64}$ que este estudo se pauta para poder entender tamanha confiança, em que transformações tão radicais nos ecossistemas poderiam trazer resultados apenas "positivos". Desta maneira, no caso estudado, mais do que uma confiança na inesgotabilidade dos recursos naturais, o que foi encontrado nos relatórios da tecnoburocracia e nas explanações da elite madeireira, uma confiança na tecnociência como "salvação".

Apesar da reprodução da imagem de uma terra paradisíaca, de um Eldorado, não era exatamente um "sentimento de inesgotabilidade do meioambiente" que estava presente nas fontes abordadas, pois tanto entre setores da elite madeireira e dos fazendeiros estava presente, também, a certeza da positividade da ação tecnocientificamente orientada, ou seja, uma confiança no progresso. A natureza ainda era um grande armazém, mas agora deveria ser gerido pelos seres humanos, com o uso da tecnologia e, em especial pós 1930, com a ação interventora do Estado.

\footnotetext{
${ }^{61}$ Ibidem.

${ }^{62}$ INP, 1956, op. cit., p. 17.

${ }^{63}$ INP, 1966, op. cit., p. 16.

${ }^{64}$ MORIN, op. cit.
} 


\section{Uma floresta heterogênea: A FOM}

A diferença entre a grande biodiversidade das florestas tropicais e subtropicais e a maior homogeneidade das florestas temperadas foi destacada nas obras dos viajantes. Mesmo no século XIX nas áreas coloniais, que recebiam imigração da Europa, procurava-se, até mesmo para atrair imigrantes, comparar ou equivaler as florestas brasileiras com as europeias. Mas, na presença da floresta, o espanto com a diversidade vegetal era uma constante. Em tais áreas coloniais tornou-se comum uma diferenciação entre "mata branca" e "mata preta", a primeira era sem araucária, em geral, Floresta Estacional Semidecidual e a segunda era a mata de araucárias, ou Floresta Ombrófila Mista. ${ }^{65}$

No século XX, uma abordagem científica procurava construir uma classificação "neutra" que capturasse as características intrínsecas ao mundo biofísico. Assim, o geógrafo Reinhard Maack, buscando fazer uma classificação do "revestimento florestal do Paraná", estabelece como uma de suas categorias a "Região das matas de araucária [...]: A formação de araucária constitui uma parte especial da mata pluvial subtropical, cujo desenvolvimento se relaciona intimamente à altitude". ${ }^{66}$ Identifica a variedade de paisagens e de composições florísticas que formariam a "mata de araucária", apontando, inclusive, que segundo "Hertel, pode-se designar a formação de araucárias como associação Araucária-Podocarpus-Ilex-Ocotea (Phoebe).” ${ }^{7}$

Miguel Mundstock Xavier de Carvalho faz uma descrição biogeográfica da Floresta com Araucárias, e explicita que um de seus objetivos é

[...] demonstrar as características biológicas e históricas peculiares da floresta de araucária, e dessa maneira entender como A ferro e fogo não pôde dar conta, na verdade, como sugere [Dean], das questões próprias a essa formação florestal. A floresta de araucária, apesar de ter uma série de características naturais e de padrões de assentamento humano semelhantes aos outros ecossistemas da Mata Atlântica abordados por Warren Dean, apresenta também questões fundamentalmente diferentes, tanto em relação aos seus aspectos biológicos ou ecológicos, quanto em relação à história da exploração desse ecossistema. ${ }^{68}$

\footnotetext{
${ }^{65}$ NODARI, Eunice Sueli. A Floresta com Araucárias: percepções distintas nos séculos XIX e XX. In: FUNES, Eurípedes; RIOS, Kênia Souza. [et al]. (Org.). Natureza e Cultura: capítulos de História Social. Fortaleza - CE: Expressão Gráfica e Editora, 2013, v. 1, p. 122-130.

${ }^{66}$ MAACK, Reinhard. Geografia física do Estado do Paraná. 2. ed. Rio de Janeiro: J. Olympio, Curitiba: Secretaria da Cultura e do Esporte do governo do Estado do Paraná, 1981. p. 242.

${ }^{67}$ Ibidem, p. 244.

${ }^{68}$ CARVALHO, Miguel Mundstock Xavier de. 0 desmatamento das florestas de araucária e o Médio Vale do Igua-
} 
Pois considera que:

Embora a floresta de araucária também seja incluída legalmente nesse conjunto de ecossistemas chamado Mata Atlântica, Warren Dean fez ao longo de A ferro e fogo muito poucas considerações sobre essa floresta subtropical. Levando-se em conta os limites propostos hoje para a Mata Atlântica, que abrangia originalmente $1.350 .000 \mathrm{~km}^{2}$, distribuídos em 17 Estados, não é de se estranhar que Warren Dean na verdade não tenha conseguido dar conta da extensão e diversidade da Mata Atlântica. Na prática, a análise de Warren Dean se relaciona com a Mata Atlântica contida nos atuais São Paulo, Rio de Janeiro, Minas Gerais, Espírito Santo, e ainda no Sul da Bahia e Norte do Paraná. ${ }^{69}$

Não é o objetivo deste trabalho fazer uma história da biogeografia e das controvérsias científicas em torno da classificação biogeográfica, do que hoje chamamos de Floresta Ombrófila Mista. Mas sim, chamar a atenção para que o mundo natural não pode ser tomado como uma invariante, ele deve ser entendido em sua diversidade e dinâmica próprias, mas também, como elementos que são continuamente ressignificados. Não devemos tomar de forma ingênua os discursos das ciências naturais, como se estes expressassem a "natureza" e não fossem produtos culturais e de relações de poder..$^{70}$ Este é um dos motivos pelos quais, mesmo os elementos "naturais", não devem ser apreciados como "objetos naturais". Afinal, Jacques Le Goff vai se apoiar em Michel Foucault para afirmar que: "explicar e explicitar a história consiste em começar por apercebê-la na sua totalidade, conduzir os pretensos objetos naturais às práticas datadas e raras que os objetivam e explicar essas práticas, não a partir de um motor único, mas de todas as práticas vizinhas em que se apoiam." 71

Por exemplo, Christian Brannstrom argumenta que a Mata Atlântica, da qual parte Dean, com 1,2 milhões de quilômetros quadrados, foi definida por vários decretos presidenciais do início dos anos de 1990, com base em um mapa publicado em 1988, escala 1:5.000.000, do IBGE, mostrando os tipos de vegetação brasileira no início do século XVI, além da Floresta Ombrófila Densa, situada no litoral, incluía como parte da Mata Atlântica, a Floresta Estacional Semidecidual e a Floresta Ombrófila Mista, além de

çu: uma história de riqueza madeireira e colonizações. Dissertação (Mestrado em História) - Programa de Pós-Graduação em História da Universidade Federal de Santa Catarina - UFSC, Florianópolis, 2006. p. 85-86.

${ }^{69}$ CARVALHO, 2006, op. cit., p. 87.

${ }^{70}$ ARNOLD, David. La natureleza como problema histórico: El medio, la cultura y la expansión de Europa. Mexico: Fondo de Cultura Econômica, 2000.

${ }^{71}$ LE GOFF, Jacques. História e Memória. 4. ed. Campinas: Ed. da UNICAMP, 1996. p. 105. 
outras categorias menos significativas. Posteriormente, tal classificação foi alterada, na edição de 1993 do citado mapa, retirando-se as menções à Mata Atlântica, mas graças, em grande parte, ao lobby ambientalista, principalmente de ONGs como a SOS Mata Atlântica, foi a "grande Mata Atlântica" que foi oficializada nos decretos governamentais.

Analisando uma área em torno da região de Assis, em São Paulo, Brannstrom afirma que a área seria melhor compreendida como um mosaico de Cerrado, Cerradão e Floresta Estacional Semidecidual. A partir desse caso, ele infere que algumas afirmações feitas por Dean sobre a quantidade de área desflorestada, devido à determinadas atividades econômicas, devem ser revistas, pois a base da qual ele partiu (uma "Mata Atlântica" biologicamente, demasiadamente homogênea) não contemplava a diversidade arbórea real da região estudada. ${ }^{72}$ Mas o que gostaríamos de destacar é o fato da delimitação da Mata Atlântica, atualmente vigente em termos legais, ser mais o resultado de embate de poderes do que de um rigoroso trabalho de biogeografia, mostrando como aquilo que parecia, sumamente biológico, é, também, e não somente, uma produção cultural..$^{73}$

Quando adotamos uma perspectiva processual, rompe-se a dicotomia entre uma história sociocultural, atenta às descontinuidades, e uma história ambiental, que ficaria presa em um determinismo de longa duração. Dicotomia na qual Alain Corbin parece que estava preso:

É tempo, para os historiadores, de reexaminar a noção de prisão de longa duração e os ritmos defasados da temporalidade braudeliana; estes últimos impõem a imagem de rios, mais ou menos rápidos e agitados, que não misturam suas águas. Convicção que torna difícil assinalar as gêneses, traçar as genealogias e, sobre tudo, detectar a coerência das representações tais como se estruturam em uma determinada época; em suma, trata-se de uma modelo que opõe um obstáculo dificilmente superável a uma autêntica história sociocultural. ${ }^{74}$

Ou seja, para Alain Corbin, a "longa duração não se enquadra na história sociocultural. Pois pressupõe um significado fixo para um fenômeno

\footnotetext{
${ }^{72}$ BRANNSTROM, Christian. Repensando a Mata Atlântica brasileira: cobertura vegetal e valor da terra no Oeste Paulista, 1900 a 1930. Varia História. Belo Horizonte, n. 26, p. 58-76, jan. 2002.

${ }^{73}$ Como afirmou S. Schama, "a natureza selvagem não se demarca a si mesma, não se nomeia. [...] Nós o fazemos". (SCHAMA, Simon. Paisagem e Memória. São Paulo: Companhia das Letras, 1996. p. 17-8.) Logo, não há "ponto de vista" que seja o da "natureza", todos eles são humanos, o que não implica que a natureza não seja dotada de agência nos processos históricos. Cf. ARNOLD, op. cit.

${ }^{74}$ CORBIN, Alain. 0 território do vazio: a praia no imaginário ocidental. São Paulo: companhia das Letras, 1989. p. 301.
} 
(uma montanha, um rio, um mar) e não atenta para as mudanças de representação que este objeto sofre durante sua existência física." ${ }^{75}$ Não se trata aqui de discutir o quanto a obra braudeliana cai em um determinismo de longa duração, mas de afirmar que não podemos prescindir, para fazer uma história ambiental, dos condicionantes ambientais de longa duração. Mas que não sejam tomados em uma relação da causalidade linear, e sim, como condicionantes inseridos em um quadro complexo de interações, "datáveis". Um bom exemplo deste problema metodológico aparece nas críticas que David Arnold faz à obra de alguns historiadores ambientais, em especial à Alfred Crosby em The Columbian Exchange. ${ }^{76}$ Para Arnold, a ênfase exagera$\mathrm{da}$, dada por Crosby nos condicionantes ambientais/biológicos, obscurece o papel ativo dos conquistadores no processo de genocídio das populações nativas americanas. Para o autor, os condicionantes ambientais devem estar sempre inseridos em suas interações socioculturais, e sempre mediados culturalmente. ${ }^{77}$

Para retomar o exemplo abordado no presente artigo, um elemento emblemático do reconhecimento da diversidade da floresta é justamente o Instituto Nacional do Pinho, que traz em seu nome o escopo de cuidar da produção da cadeia produtiva da Araucaria angustifolia, visando justamente efetuar uma racionalização do setor produtivo, estabelecendo critérios e cotas de produção, a fim de maximizar a utilização do recurso natural, enquanto bem econômico, mas mesmo tendo como escopo principal, reduzir a floresta a uma racionalidade única; logo teve que lidar com a diversidade da floresta tentando, primeiramente, racionalizar outras espécies arbóreas, depois toda a cadeia produtiva da indústria madeireira, até ser incorporado/transformado no Instituto Brasileiro de Desenvolvimento Florestal, em 1967, o qual tinha por função, além de "desenvolver a indústria florestal", cuidar e preservar os "parques nacionais" e os recursos naturais, funções que entravam em contradição dentro do IBDF. ${ }^{78}$

Uma série de pesquisas demonstram as diferentes formas de apropriação material e simbólica da floresta, que levam a diferentes formas de

\footnotetext{
${ }^{75}$ HEYNEMANN, Cláudia. Floresta da Tijuca: natureza e civilização no Rio de Janeiro - século XIX. Rio de Janeiro: Secretaria Municipal da Cultura, 1995.

${ }^{76}$ CROSBY, Aldred W. The Columbian Exchange: Biological and Cultural consequences of 1492. EUA: Greenwood Publishing Group, 2003.

${ }^{77}$ ARNOLD, op. cit.

${ }^{78}$ HOCHSTETLER, Kathryn; KECK, Margaret E. Greening Brazil: Environmental Activism in State and Society. Durham: Duke University Press, 2007.
} 
classificação e vivência dos ambientes. ${ }^{79}$ Por exemplo, o sistema de faxinais: no qual pequenos produtores rurais desenvolvem a criação de gado em meio à floresta em espaços comunais. Os produtores que procuram, ainda hoje, manter tal prática, a apresentam como uma prática ecologicamente sustentável e socialmente justa, de convívio com a floresta. ${ }^{80}$ Sendo um elemento emblemático do deslocamento da ênfase para a heterógena sociobiodiversidade da Floresta com Araucárias.

A heterogeneidade da Floresta Ombrófila Mista e as diferenças culturais de formas de apropriação acabaram se impondo a uma racionalidade reducionista, que reduzia a floresta a seu valor econômico..$^{81}$ Todavia, não é o caso da diversidade da floresta simplesmente sendo reconhecida pelos seres humanos e sim da construção de novas formas de representação da floresta que reconfiguram os elementos dando ênfase e positivando as diferenças. ${ }^{82}$

\section{Considerações Finais}

No último quartel do século $\mathrm{XX}$, a biodiversidade emerge enquanto um grande valor positivo. Visto como um valor econômico, um recurso, como algo que garante a saúde ambiental de nosso "ecossistema planetário", ou como um bem em si, dado o direito de outros seres de existirem.

Os argumentos em prol da preservação da Floresta Ombrófila Mista passam por sua biodiversidade, uma floresta heterogênea ${ }^{83}$; mas na primeira metade do século XX, as políticas florestais, para tal ecossistema, passavam justamente pela percepção dela enquanto uma floresta homogênea. $O$ que nos lembra que é sempre o ser humano que classifica os ambientes.

\footnotetext{
${ }^{79}$ NODARI, Eunice Sueli. Unidades de Conservação de Proteção Integral: solução para a preservação? Floresta com Araucárias em Santa Catarina. Esboços (UFSC), v. 18, p. 96-117, 2011; LOPES, A. R. S.; NODARI, E. S. O que é da natureza não se mexe: memória e degradação ambiental na Lagoa de Sombrio-SC (1960-2010). História Oral (Rio de Janeiro), v. 15, p. 303-330, 2012; BRANDT, Marlon; NODARI, Eunice. Comunidades tradicionais da Floresta de Araucária de Santa Catarina: territorialidade e memória. História Unisinos, v. 15, p. 80-90, 2011. CARVALHO, 2006, op. cit.

${ }^{80}$ LUPEPSA, Eliane Crestiane; SCHÖRNER, Ancelmo. Organização socioespacial: faxinalenses e agricultores de Jesuíno Marcondes, Prudentópolis/PR (1987-2007). Revista Tempo, Espaço e Linguagem (TEL), v. 1, n. 3, p.11-41, set./dez. 2010.

${ }^{81}$ MORIN, op. cit., p. 112.

${ }^{82}$ Tal transformação está inserida no horizonte utópico da construção de uma racionalidade ambiental, mas não implica necessariamente na realização de uma nova racionalidade. Ver: LEFF, Enrique. Racionalidade ambiental: a reapropriação social da natureza. Rio de Janeiro: Civilização Brasileira, 2006.
}

${ }^{83}$ BRASIL, 2010, op. cit., p. 14. 
Como afirma Simon Schama ${ }^{84}$, são sempre os seres humanos que a classificam a natureza: na primeira metade do século XX a floresta parece ser inesgotável, primeiro por sua abundância, mas logo tal abundância se mostrou escassa com a instalação de um moderno complexo industrial madeireiro, mas que continuava a perceber a floresta enquanto inesgotável, não porque ela não estivesse ou pudesse ser esgotada, mas porque a tecnologia da silvicultura seria capaz, quando corretamente incentivada pelo governo, de garantir que "nunca se extingam as SERRARIAS DO BRASIL". ${ }^{85}$

Assim, todas as representações sobre o mundo natural são sempre humanas e dizem sobre a relação das sociedades humanas para com seus ambientes, todavia, isso não significa que o mundo natural não age. Diante de um projeto que quase extinguiu a Floresta Ombrófila Mista ao tentar reduzi-la a um grande cultivo de madeira a ser explorado, podemos acompanhar o retorno do recalcado (do que foi jogado às margens), com as novas políticas de conservação de tal ecossistema, enfatizando sua sociobiodiversidade. ${ }^{86}$

Partir de ecossistemas ou outros recortes espaciais "naturais" para construir uma história ambiental pareceu, em um primeiro momento, um grande trunfo da história ambiental ${ }^{87}$, para poder efetuar uma narrativa em que os seres humanos não são tudo e que ultrapasse as fronteiras nacionais. ${ }^{88}$ Todavia, naturalizar os recortes no mundo natural é uma armadilha metodológica, que a maioria dos historiadores ambientais aprendeu a enfrentar. Aqui nos aproximamos de Marshall Sahlins ${ }^{89}$, para abordar elementos de longa duração não como invariantes, mas em uma relação dialética entre agência e estrutura, da qual o mundo não-humano não está ausente. David Blackbourn coloca o problema aqui enfrentado da seguinte forma:

Aqueles que tentam trazer para a história ambiental os ganhos conceptuais da história cultural arriscam ser desafiados por praticantes materialistas severos, sair demais das fontes literárias, ou habitar muito tempo na 'paisagem construída' é correr o risco de carga do impressionismo branco [...] Há, contudo, desafios, ambos práticos e conceptuais, noutra direção. Onde está a fronteira entre história e história natural: Até que ponto podemos considerar um rio ou uma espécie não humana, um sujeito, e não apenas um objeto de

\footnotetext{
${ }^{84}$ SCHAMA, op. cit., p. 20.

${ }^{85}$ PEREIRA, op. cit., p. V (grifo no original)

${ }^{86}$ NODARI, 2012, op. cit.

${ }^{87}$ DEAN, op. cit.

${ }^{88}$ COULTER, Kimberly; MAUCH, Christof. Introdução In: cessidades e oportunidades. RCC Perspectives, 2011. p. 5-8. p. 6.

${ }^{89}$ SAHLINS, op. cit.
} 
estudo de nosso trabalho, e mesmo assim estarmos a escrever história [...] Ou. Citando Tim Michael [...]: Pode um mosquito falar? ${ }^{90}$

O pequeno exemplo aqui trabalhado procura mostrar que o "mosquito" ou a "Floresta com Araucárias" não podem falar, mas podem ser sujeitos ativos de processos históricos, nos quais os seres humanos fazem parte.

No que tange à escala de análise, acompanhamos Jacques Revel ${ }^{91}$ ao não priorizar uma escala, mas em aprender as conexões transescalares ${ }^{92}$, o que em história ambiental é ainda mais forte, em especial pelo desafio de abarcar processo de longuíssima duração, como afirmar Blackbourn,

A história ambiental precisa ser escrita em escalas temporais, da história profunda à história de uma crise, como um incêndio ou uma inundação, que abre uma janela para questões maiores. A história ambiental convida ao que Jacques Revel chamou de jeu d' echelles, ou jogando com escalas. Essa é uma das suas virtudes. ${ }^{93}$

Não há uma escala ou recorte prévio que deva ser abordado sem questionamento prévio. O que só confirma algo que há muito encontramos nos debates metodológicos historiográficos, a saber: os recortes espaciais devem ser construídos junto com o "objeto" ${ }^{94}$ e não ser algo a priori, em qualquer boa narrativa histórica.

Artigo recebido para publicação em 08/10/2015

Artigo aprovado para publicação em 20/11/2015

\footnotetext{
${ }^{90}$ BLACKBOURN, David. História Ambiental e Outras Histórias In: COULTER, MAUCH,. op. cit.,p. 26-27.

${ }^{91}$ REVEL, Jacques. Microanálise e a construção do social. In: . (Org.). Jogos de escalas: A experiência da microanálise. Rio de Janeiro: FGV, 1998. p. 15-38.

${ }^{92}$ BERKES, Fikret. Ligações institucionais trans-escalares: para uma reversão de perspectivas. In: OSTRO, E. et al. (ed.). A tragédia dos comuns. Washington: National Academy Press, 2002. p. 293-321.

${ }^{93}$ BLACKBOURN, 2011, op. cit., p. 26.

${ }^{94}$ SILVA, Francisco Carlos Teixeira da; LINHARES, Maria Yedda. Região e História Agrária. Estudos Históricos, Rio de Janeiro, v. 8, n. 15, p. 17-26, 1995.
} 